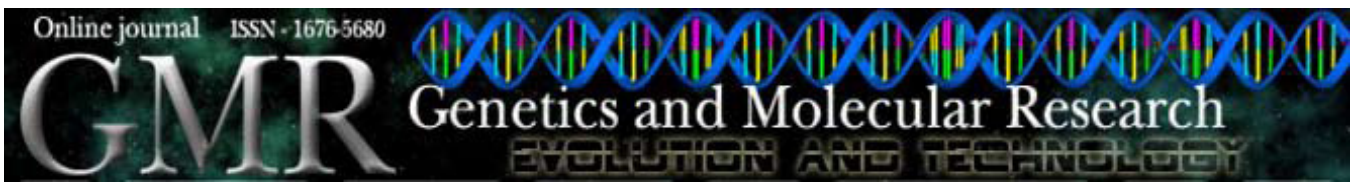

\title{
Genotyping in the Brazilian Criollo Horse Stud Book: resources and perspectives
}

\author{
M.A.P. Costa ${ }^{1}$, R.M.C. Bressel ${ }^{2}$, D.B. Almeida ${ }^{1}$, P.A. Oliveira ${ }^{3}$, L.N. Bassini ${ }^{3}$, \\ C.G.A. Moreira ${ }^{4}$, V.H.B. Manzke ${ }^{5}$, F. Siewerdt ${ }^{6}$ and H.L.M. Moreira ${ }^{7}$ \\ ${ }^{1}$ Programa de Pós-Graduação em Zootecnia, \\ Departamento de Zootecnia, Universidade Federal de Pelotas, \\ Pelotas, RS, Brasil \\ ${ }^{2}$ Laboratório de Análises DETECTA, Centro de Biotecnologia, \\ Universidade Federal de Pelotas, Pelotas, RS, Brasil \\ ${ }^{3}$ Laboratório de Engenharia Genética Animal, Centro de Biotecnologia, \\ Universidade Federal de Pelotas, Pelotas, RS, Brasil \\ ${ }^{4}$ Programa de Pós-Graduação em Genética e Biologia Molecular, \\ Departamento de Genética, Universidade Federal do Rio Grande do Sul, \\ Porto Alegre, RS, Brasil \\ ${ }^{5}$ Conjunto Agrotécnico Visconde da Graça, Universidade Federal de Pelotas, \\ Pelotas, RS, Brasil \\ ${ }^{6}$ Department of Animal and Avian Sciences, \\ Animal Sciences Center, University of Maryland, College Park, MD, USA \\ ${ }^{7}$ Departamento de Zoologia e Genética, \\ Universidade Federal de Pelotas, Pelotas, RS, Brasil \\ Corresponding author: M.A.P. Costa \\ E-mail: mapc.mv@gmail.com
}

Genet. Mol. Res. 9 (3): 1645-1653 (2010)

Received April 18, 2010

Accepted June 14, 2010

Published August 24, 2010

DOI 10.4238/vol9-3gmr854

ABSTRACT. The goal of this research was to evaluate the ability of the genotyping information available in the Brazilian Criollo Horse Stud Book to describe the genetic variability of the breed and the exclusion probability determined in comparative tests. Altogether, two softwares were used in the analyses of the available genotypes: Cervus 3.0.3 and Genepop 4.0. Eight microsatellite markers totaled 109 alleles, 
with an average of $13.6 \pm 0.6$ alleles per locus. Large differences between expected and observed heterozygosity were ubiquitous $(0.821$ \pm 0.07 and $0.470 \pm 0.17$, respectively). Although the estimated null allele frequency caused initial concern $(0.284 \pm 0.199)$, it is likely that it was a reflection of the inbreeding coefficients found $(0.432 \pm$ 0.184). All loci showed significant deviation from Hardy-Weinberg equilibrium, with heterozygote deficit $(\mathrm{P}<0.0001)$ and genotypic linkage disequilibrium with at least one marker. The high polymorphic information content $(0.798 \pm 0.088)$ could not warrant exclusion power for three loci (HMS7, HMS6 and HTG4) above 50\% (0.491 \pm 0.158$)$. However, combined exclusion probability reached $99.61 \%$, a level close to ideal. The results demonstrate the excellent performance of the markers assessed in describing the genetic status of the breed and suggest the considerable ability to establish parentage.

Key words: SSR; Parentage testing; Genetic monitoring

\section{INTRODUCTION}

The raising of horses on the American continent started with the first expeditions of conquerors and colonists. The genetic background was mainly formed by horses of Iberian origin that spread throughout the New World and gave rise to the different breeds (Diaz et al., 2002; Kelly et al., 2002; Mirol et al., 2002). Among these, the Criollo breed constitutes a select group of animals recognized by their endurance (Cardellino, 2000; Diaz et al., 2002), hardiness (Diaz et al., 2002; Kelly et al., 2002), and fitness for cattle work (Cardellino, 2000; Kelly et al., 2002). Large remnant herds of abandoned or lost horses molded its features after centuries of natural selection under adverse environmental conditions (Kelly et al., 2002).

In 1932, breeders of the Rio Grande do Sul State founded the ACCC/Association of Criollo Horse Breeders (ABCCC, 1941), whose aim was to direct the future course of selection and preserve the pedigree of the breed (ABCCC, 2004). Initially, bands were selected and included in a provisional registration because of its racial pattern, totaling 1387 animals - 131 stallions, 1228 mares and 28 foals. Thus, since 1941, the Brazilian stud book remained closed, accepting only products from the founder herd (ABCCC, 1941). The organization of the International Federation of Criollo Horse Breeders (FICCC), in the 1950s, provided the expansion of its boundaries, to include Argentina, Brazil, Chile, Cuba, Paraguay, and Uruguay, as founder countries (FICCC, 2010). Annually, frequent migrations are recorded between affiliated countries, in parallel with international scope events.

In livestock, the use of paternity testing primarily aims to confirm the relationship between individuals (Lee and Cho, 2006; Paredes et al., 2009) and to help in criminal investigations (Tozaki et al., 2001; Dimsoski, 2003; Budowle et al., 2005; Lee and Cho, 2006; van de Goor et al., 2010). Such assays have wide acceptance among the entities responsible for keeping pedigree registries (Jamieson and Taylor, 1997; Tozaki et al., 2001; Jakabová, 2002; Luís et al., 2002; Lee and Cho, 2006). Genetic characterization is the first step in the conservation of breeds (Solis et al., 2005; Plante et al., 2007). This information could serve as a guideline for future breeding strategies (Solis et al., 2005; Plante et al., 2007). 
The goal of this study was to evaluate the current genotypic data in the Brazilian Criollo Horse Stud Book and the ability to use this information to describe the genetic variability of the breed and to predict the probability of exclusion determined in comparative tests.

\section{MATERIAL AND METHODS}

Currently, $\mathrm{ABCCC}$ requires the genotyping of a candidate reproducer for registration in the stud book. Qualified technicians collect tufts of hair from the base of the tail from selected animals at the time of final morphological assessment. Later, this material is sent to laboratories accredited by the organization. However, matrices are not subject to such requirements. Thus, a total of 2542 genotyped stallions were sampled in this study between the years 2005 and 2008 .

Following the recommendation of the International Society of Animal Genetics (ISAG, 2003) and the Equine Genetics Standing Committee, a set of eight microsatellite markers is routinely employed for horse genotyping. The description of their respective locations, primer sequences, fluorescent dye, and references are presented in Table 1. ASB2, the ninth marker on the ISAG list, was not used because no fragments were produced after polymerase chain reaction (PCR) amplification.

\begin{tabular}{|c|c|c|c|}
\hline$E c a$ & Locus & Primer sequence $\left(5^{\prime} \rightarrow 3^{\prime}\right)$ & Reference \\
\hline 1 & HMS7 & $\begin{array}{l}\text { F: [FAM]CAGGAAACTCATGTTGATACCATC } \\
\text { R: TGTTGTTGAAACATACCTTGACTGT }\end{array}$ & (Guerin et al., 1994) \\
\hline 4 & HMS6 & $\begin{array}{l}\text { F: [HEX]GAAGCTGCCAGTATTCAACCATTG } \\
\text { R: CTCCATCTTGTGAAGTGTAACTCA }\end{array}$ & (Guerin et al., 1994) \\
\hline 8 & AHT5 & $\begin{array}{l}\text { F: [HEX]ACGGACACATCCCTGCCTGC } \\
\text { R: GCAGGCTAAGGAGGCTCAGC }\end{array}$ & (Binns et al., 1995) \\
\hline 9 & HMS3 & $\begin{array}{l}\text { F: [FAM]CCAACTCTTTGTCACATAACAAGA } \\
\text { R: CCATCCTCACTTTTTCACTTTGTT }\end{array}$ & (Guerin et al., 1994) \\
\hline 9 & HTG4 & $\begin{array}{l}\text { F: [FAM]CTATCTCAGTCTTGATTGCAGGAC } \\
\text { R: CTCCСТCССТCCCTCTGTTCT }\end{array}$ & (Ellegren et al., 1992) \\
\hline 21 & HTG10 & $\begin{array}{l}\text { F: [FAM]CAATTCCCGCCCCACCCCCGGCA } \\
\text { R: TTTTTATTCTGATCTGTCACATTT }\end{array}$ & (Marklund et al., 1994) \\
\hline 24 & AHT4 & $\begin{array}{l}\text { F: [FAM]AACGCCTGAGCAAGGAAGT } \\
\text { R: GCTCCCAGAGAGTTTACCCT }\end{array}$ & (Binns et al., 1995) \\
\hline 30 & VHL20 & $\begin{array}{l}\text { F: [FAM]CAAGTCCTCTTACTTGAAGACTAG } \\
\text { R: AACTCAGGGAGAATCTTCCTCAG }\end{array}$ & (van Haeringen et al., 1994) \\
\hline
\end{tabular}

Eca $=$ Equus caballus autosomal chromosomes; $\mathrm{F}=$ sequence of forward primer; $\mathrm{R}=$ sequence of reverse primer; $[-]=$ fluorescent dye.

Two multiplex sets allowed the amplification of genomic stretches in only two PCR: AHT4, AHT5, HMS6, HMS7, HTG4 and VHL20, and HMS3 and HTG10. Standardized reactions to a total volume of $15 \mu \mathrm{L}$ contained two hair roots, $0.2 \mathrm{mM}$ of each dNTP, $0.5 \mu \mathrm{L}$ Taq DNA polymerase ( $5 \mathrm{U} / \mu \mathrm{L}$, Invitrogen Inc.), $50 \mathrm{mM} \mathrm{KCl}, 10 \mathrm{mM}$ Tris- $\mathrm{HCl}, \mathrm{pH} 8.4,1.5 \mathrm{mM}$ $\mathrm{MgCl}_{2}$, and $0.2 \mathrm{mM}$ of each primer. A PTC-100 Peltier Thermal Cycler (MJ Research) was programmed to perform a pre-denaturation at $95^{\circ} \mathrm{C}$ for $10 \mathrm{~min}$, followed by a sequence of 30 cycles at $95^{\circ} \mathrm{C}$ for $30 \mathrm{~s}, 60^{\circ} \mathrm{C}$ for $30 \mathrm{~s}$ and $72^{\circ} \mathrm{C}$ for $60 \mathrm{~s}$, and ending with a final extension at $72^{\circ} \mathrm{C}$ for 60 min. An ABI PRISM ${ }^{\circledR} 377$ DNA Sequencer was used to determine the size of the amplicons with the aid of the GENESCAN Analysis software, version 3.12, and an internal molecular weight standard (GeneScan Rox 500 ${ }^{\circledR}$ ), all from the same manufacturer (Applied Biosystems, USA). 
Altogether, two softwares were used to analyze the available genotypes. Cervus 3.0.3 (Kalinowski et al., 2007) was employed to obtain observed $\left(H_{o}\right)$ and expected $\left(H_{e}\right)$ heterozygosity, polymorphic information content (PIC), average exclusion probability for one candidate parent (EP1), average exclusion probability for one candidate parent given the genotype of a known parent of the opposite sex (EP2), average exclusion probability for a candidate parent pair (PP), combined exclusion probability (CP), and estimated null allele frequency (NF). Genepop 4.0 (Rousset, 2008) provided the exact test of Hardy-Weinberg equilibrium, deficiency or excess of heterozygotes, and inbreeding coefficients or $F_{\text {is }}$ (Weir and Cockerham, 1984).

\section{RESULTS}

A total of 109 alleles were identified across all evaluated loci, with an average of $13.6 \pm 0.6$ alleles per locus. HTG10 and HTG4 were the extremes with regard to the number of alleles, 17 and 10, respectively. It was evident that there was a great variation not only in the number of alleles per locus, but also in the distribution of their frequencies (Table 2). While three of the seventeen alleles in HTG10 (L, M and K) represented $54.1 \%$ of the observed frequency for this locus, in HTG4 an equal number (J, K and L) corresponded to $90.7 \%$ of occurrences between its ten alleles. For the same loci, 64.7 and $60.0 \%$ of the alleles had frequencies less than $5 \%$.

Table 2. Distribution of observed allelic frequencies (\%) at microsatellite loci used in genotyping of the Criollo
horse breed in Brazil.
\begin{tabular}{lcccccccc} 
Allele & HMS7 & HMS6 & AHT5 & HMS3 & HTG4 & HTG10 & AHT4 & VHL20 \\
\hline C & - & - & - & - & - & 0.22 & - & - \\
D & - & - & - & - & - & 0.73 & 0.08 & - \\
E & - & - & - & - & - & 2.16 & 0.33 & 0.53 \\
F & 0.16 & - & 0.30 & - & - & 3.70 & 0.89 & 0.96 \\
G & 0.31 & 0.14 & 4.11 & 0.28 & 0.10 & 4.56 & 18.49 & 1.36 \\
H & 0.83 & 0.18 & 7.10 & 16.88 & 0.18 & 7.26 & 2.95 & 21.48 \\
I & 1.44 & 0.26 & 5.92 & 10.60 & 0.45 & 4.35 & 12.80 & 3.01 \\
J & 5.55 & 0.89 & 8.36 & 0.59 & 38.95 & 5.06 & 9.76 & 2.97 \\
K & 15.97 & 11.15 & 15.17 & 0.96 & 38.12 & 13.73 & 6.31 & 26.10 \\
L & 31.77 & 9.38 & 13.32 & 6.20 & 13.63 & 22.99 & 7.59 & 17.01 \\
M & 16.03 & 22.70 & 13.04 & 12.33 & 5.04 & 17.39 & 25.83 & 7.87 \\
N & 12.61 & 2.26 & 24.43 & 7.73 & 1.69 & 9.26 & 9.95 & 3.15 \\
O & 9.99 & 19.06 & 7.24 & 16.38 & 1.51 & 1.93 & 2.07 & 7.61 \\
P & 0.61 & 32.81 & 0.57 & 20.75 & 0.33 & 3.42 & 1.28 & 3.82 \\
Q & 4.41 & 1.10 & 0.39 & 4.90 & - & 2.50 & 1.26 & 3.28 \\
R & 0.33 & 0.08 & 0.04 & 2.22 & - & 0.67 & 0.41 & 0.79 \\
S & - & - & 0.02 & 0.18 & - & 0.08 & - & 0.06 \\
\hline
\end{tabular}

Roman letters represent alleles according to Budowle et al. (2005).

When all loci were ordered by deviance between the $H_{e}$ and $H_{o}$ (Table 3), AHT5 and HTG4 contrasted strongly with VHL20 and AHT4, and the same ranking was preserved for the inbreeding coefficients and estimated null allele frequencies in spite of a rearrangement between markers HTG4 and AHT5. $H_{e}$ showed a smaller amplitude of variation (HTG4:0.681 $\leq H_{e} \leq 0.874$ :HTG10) than $H_{o}$ (HTG4:0.245 $\leq H_{o} \leq 0.642$ :AHT4). On average, $82.1 \%$ of heterozygotes were expected per locus, while only $47.0 \%$ were observed. 
Table 3. Summary of the descriptive ability of microsatellite markers routinely employed in Brazilian paternity testing for the Criollo horse breed about genetic variability and exclusion probabilities.

\begin{tabular}{lccccccccc}
\hline Locus & $\mathrm{N}$ & $H_{o}$ & $H_{e}$ & PIC & EP1 & EP2 & PP & $F_{i s}$ & NF \\
\hline HMS7 & 13 & 0.453 & 0.817 & 0.795 & 0.472 & 0.647 & 0.829 & 0.446 \\
HMS6 & 12 & 0.487 & 0.783 & 0.751 & 0.402 & 0.581 & 0.766 & 0.377 & 0.290 \\
AHT5 & 14 & 0.402 & 0.860 & 0.845 & 0.562 & 0.722 & 0.886 & 0.533 \\
HMS3 & 13 & 0.506 & 0.862 & 0.847 & 0.564 & 0.723 & 0.886 & 0.413 & 0.364 \\
HTG4 & 10 & 0.245 & 0.681 & 0.624 & 0.264 & 0.426 & 0.604 & 0.640 & 0.483 \\
HTG10 & 17 & 0.467 & 0.874 & 0.862 & 0.600 & 0.751 & 0.908 & 0.466 & 0.308 \\
AHT4 & 15 & 0.642 & 0.852 & 0.836 & 0.546 & 0.709 & 0.877 & 0.246 & 0.139 \\
VHL20 & 15 & 0.561 & 0.839 & 0.821 & 0.520 & 0.686 & 0.861 & 0.332 & 0.199 \\
\hline
\end{tabular}

$\mathrm{N}=$ number of observed alleles per locus; $H_{o}=$ observed heterozygosity; $H_{e}=$ expected heterozygosity; PIC = polymorphic information content; EP1 = average exclusion probability for one candidate parent; EP2 = average exclusion probability for one candidate parent given the genotype of a known parent of the opposite sex; PP= average exclusion probability for a candidate parent pair; $F_{i s}=$ inbreeding coefficient (Weir and Cockerham, 1984); $\mathrm{NF}=$ estimated null allele frequency.

All loci showed significant deviations from Hardy-Weinberg equilibrium and heterozygote deficit $(\mathrm{P}<0.0001)$. Likewise, genotypic linkage disequilibrium was ubiquitous (Table 4), reaching a maximum in AHT5 linked to six markers, and near significance with the seventh, HMS3 $(\mathrm{P}=0.078)$. However, the latter locus was the only one to show disequilibrium with just one marker. With the exception of HTG4 and HTG10, which were linked to five and two markers, respectively, the remainder showed a relationship with four other loci.

Table 4. Combined exclusion probability ${ }^{1}$ and genotypic linkage disequilibrium ${ }^{2}$ of microsatellite loci used in paternity testing for the Criollo horse breed in Brazil.

\begin{tabular}{lcccccccc}
\hline & HTG10 & HMS3 & AHT5 & AHT4 & VHL20 & HMS7 & HMS6 & HTG4 \\
\hline HTG10 & $\mathbf{0 . 6 0 0}$ & 0.6391 & 0.0000 & 0.3108 & 0.3586 & 0.5657 & 0.0000 & 0.1519 \\
HMS3 & & $\mathbf{0 . 8 2 5 6}$ & 0.0783 & 0.4583 & 0.5172 & 0.1154 & 0.0000 & 0.1993 \\
AHT5 & & $\mathbf{0 . 9 2 3 6}$ & 0.0000 & 0.0000 & 0.0000 & 0.0000 & 0.0000 \\
AHT4 & & & & $\mathbf{0 . 9 6 5 3}$ & 0.0000 & 0.0142 & 0.8927 & 0.0000 \\
VHL20 & & & & & $\mathbf{0 . 9 8 3 4}$ & 0.0370 & 0.1424 & 0.0471 \\
HMS7 & & & & & & $\mathbf{0 . 9 9 1 2}$ & 0.9842 & 0.0000 \\
HMS6 & & & & & & & $\mathbf{0 . 9 9 4 7}$ & 0.0000 \\
HTG4 & & & & & & & & $\mathbf{0 . 9 9 6 1}$ \\
\hline
\end{tabular}

${ }^{1}$ Combined exclusion probabilities are on the diagonal and increase from the upper left to lower right; ${ }^{2}$ genotypic linkage disequilibrium: $\mathrm{P}$ values are above the diagonal.

Overall, the markers reached a PIC above 0.600 , which allowed an average of 0.798 \pm 0.088 . HTG10 and HMS3 were the most informative genomic stretches, unlike HMS6 and HTG4. The same order corresponded directly for all average exclusion probabilities (EP1, EP2 and PP). Just three loci (HMS7, HMS6 and HTG4) obtained exclusion levels below 50\% (EP1), whereas the others were well above the average for the set $\left(\mu_{E P I}: 0.491 \pm 0.158\right)$. The inclusion of the individual probabilities to estimate the combined probability obtained acceptable exclusion power (CP1: 0.9961), but only if genotypic information of the other parent (EP2) was incorporated into the model, combined probability would reach ideal exclusion power for one (CP2: 0.9999) or both parents $(\mathrm{CP} 3>0.9999)$.

Expectations were excessively high for the estimated NF and $F_{i s}$, with average values 
of $0.284 \pm 0.199$ and $0.432 \pm 0.184$ for marker sets (in same sequence), so that HTG4 (0.483; $0.640)$ and AHT5 $(0.364 ; 0.533)$ were considerably higher than VHL20 $(0.199 ; 0.332)$ and AHT4 $(0.139 ; 0.246)$, which established the lower limits.

\section{DISCUSSION}

The number of alleles is a representative measure of genetic diversity (Plante et al., 2007). Thus, the high polymorphism found among Criollo horses in this study is striking, even more so when one compares the average number of alleles per locus with other national (Luis et al., 2007b) and foreign herds (Kelly et al., 2002; Luis et al., 2007b; Paredes et al., 2009), or even other breeds (Bowling et al., 1997; Jakabová, 2002; Solis et al., 2005; Lee and Cho, 2006; Kakoi et al., 2007; Luis et al., 2002, 2007a,b; Plante et al., 2007; Giacomoni et al., 2008; Perez-Gutierrez et al., 2008; Thirstrup et al., 2008; Bomcke and Gengler, 2009; LeRoy et al., 2009). This particularity can be attributed to the short period since the closing of its stud book or the constant migration of animals (Thirstrup et al., 2008) solely allowed between countries affiliated with FICCC. Even though the order between the most frequent alleles had not been kept in herds from Uruguay (Kelly et al., 2002) and Chile (Paredes et al., 2009), it is clear that some alleles were exclusive to Criollo horses in this study.

Usually, alterations of genotypic proportions can be due to population substructuration (Waits et al., 2001; Luís et al., 2002; Dakin and Avise, 2004), linkage to traits under selection (Bowling et al., 1997; Dakin and Avise, 2004; Paredes et al., 2009), favoring environmental constraints (Diaz et al., 2002), differences in sex-linked selection intensity (Vila et al., 2001; Mirol et al., 2002; Luis et al., 2007a,b; Paredes et al., 2009), or mating between related individuals (Dakin and Avise, 2004; Paredes et al., 2009). In addition, other factors inherent to the assessed data, such as the non-sampling of females, constant migration of individuals, regional differences in environment, and selection objectives, should also be considered. Deviation from Hardy-Weinberg equilibrium and heterozygote deficit were already described in previous publications evaluating Criollo horses (Kelly et al., 2002; Luis et al., 2007b; Paredes et al., 2009), but never in all the reported loci shown by a single study. In several other horse breeds, small differences were also described (Jakabová, 2002; Solis et al., 2005; Lee and Cho, 2006; Kakoi et al., 2007; Luis et al., 2002, 2007a; Giacomoni et al., 2008; Perez-Gutierrez et al., 2008; Thirstrup et al., 2008).

In regard to PIC in the sampled horses, average values were lower in Chilean (Paredes et al., 2009) bands and in other breeds (Jakabová et al., 2002; Lee and Cho, 2006; Kakoi et al., 2007; Luis et al., 2002, 2007a; Giacomoni et al., 2008; Bomcke and Gengler, 2009). Estimates above 0.5 are desired in virtue of its association with larger exclusion probability. Thus, ideal exclusion power of $99.95 \%$ (Tozaki et al., 2001) will be obtained with smaller number of loci. However, one of the assumptions for estimation of exclusion probability is the independent distribution of allelic frequencies between the loci (Bowling et al., 1997; Jamieson and Taylor, 1997; Marshall et al., 1998; Waits et al., 2001). Although it is believed that weak linkage between a few markers does not cause serious bias on these probabilities (Bowling et al., 1997; Marshall et al., 1998), the genotypic linkage disequilibrium among all loci under study may compromise its estimates and confidence intervals. The findings emphasize the need of additional investigation in order to identify better suited loci for the comparative tests (Bowling et al., 1997; Paredes et al., 2009). 
The exclusion power of the markers genotyped was meaningful (CP1: 0.9961), but some remarks can be made by analyzing individual probabilities. The simple replacement of HMS7 (0.4720) and HMS6 (0.4020) by others as informative as VHL20 (EP1 equal to or greater than 50\%) would allow that an upper exclusion level be obtained using only seven markers, without needing to include HTG4 (0.2640). Moreover, the inclusion of genotypic information from the other parent (EP2) would enable an even higher exclusion level using only five markers, without the necessity of relying on HMS7, HMS6 and HTG4. Alternatively, the replacement of these last three markers by others as informative as VHL20 would ensure a precision at the ideal level (CP2: 0.9999). Nevertheless, the estimates are still superior to those reported at other locations (Paredes et al., 2009) and in previous studies with different breeds (Jakabová, 2002; Luís et al., 2002; Giacomoni et al., 2008). These estimates make errors extremely unlikely (Lee and Cho, 2006; Paredes et al., 2009).

Overall, the occurrence of null alleles is limited to one or a few specific loci (Achmann et al., 2001; Dakin and Avise, 2004), not for the entire set as seen herein. ABS2, one of the markers recommended by ISAG, but not used in assays for Criollo horses, is an example of a locus with a history of null alleles (Achmann et al., 2001). Markers showing such feature should be avoided in paternity testing (Bowling et al., 1997; Jamieson and Taylor, 1997), due to an increase in the chances of false-parentage exclusion (Marshall et al., 1998; Bjornstad and Roed, 2002; Dakin and Avise, 2004). However, despite the attention attracted by estimated null-allele frequency indexes, its estimates may have been biased by heterozygote deficit or inbreeding coefficients (Dakin and Avise, 2004). This last measure was higher than those previously reported for Criollo horses (Paredes et al., 2009) as well as for other breeds (Kakoi et al., 2007; Plante et al., 2007; LeRoy et al., 2009), but never with means so high nor on all assessed loci, even in endangered populations (Luis et al., 2007a; Plante et al., 2007; Giacomoni et al., 2008; Perez-Gutierrez et al., 2008; Thirstrup et al., 2008; LeRoy et al., 2009). Management decisions, such as extensive use of groups of breeders (Mirol et al., 2002) and mating between related individuals (Paredes et al., 2009), which are common in purebred herds, could explain the high indexes observed. Moreover, the overrepresentation of certain alleles (as in HTG4) combined with the reduced number of heterozygotes, was a strong indication of unsuitable management for control of inbreeding levels.

Suitable markers for paternity testing should maintain balanced distribution of allelic frequencies because the maximum exclusion power is achieved when they are equal in frequency (Jamieson and Taylor, 1997). Thereby, the effectiveness of this test depends on population estimates of allele frequencies, regardless of gender. Although we have information only on a group of parents, males represent the animal category subjected to greater selection intensity (Vila et al., 2001; Mirol et al., 2002; Luis et al., 2007a,b; Paredes et al., 2009), where it is responsible for the dissemination of the major fraction of genetic variation. Despite bias, the available genotypes provide a good approximation of genetic variability and exclusion probability. In an ideal scenario, females should also be genotyped, but as this alternative depends on current methodology costs (Dimsoski, 2003), the simple periodic sampling of mares would suffice to monitor allele frequencies and improve the precision of ensuing analyses.

In general, the genealogical registry of breeders' associations is well documented, but genotyping can bring greater benefits, especially in cases where information is incomplete or limited (Bomcke and Gengler, 2009). Such resource can help setting goals for conservation and genetic improvement (Bjornstad and Roed, 2002; Luis et al., 2007b; Thirstrup et al., 
2008). By being a biotype probably very close to an old Iberian type (Kelly et al., 2002; Mirol et al., 2002), the importance of knowledge of the genetic variability of the Criollo breed is not limited solely to the conservation of its members, but also to that of other populations (Mirol et al., 2002; Luis et al., 2007b; Giacomoni et al., 2008; Perez-Gutierrez et al., 2008), given the representation of this ancestral group in the establishment of different modern horse breeds.

Genotyping data originating from the genealogical registry of ABCCC showed the excellent performance of microsatellite markers in describing the genetic status of the breed. Despite some limitations that were pointed out, the high exclusion power reinforces the applicability of this technique in origin control, with important confidence levels. However, three recommendations can be made from the present results: at least a representative portion of mares should also be periodically genotyped to obtain a sampling of allelic frequencies in the population regardless of gender; future studies should be aimed at replacing less informative loci and at identifying those that better meet the requirements of the probabilistic model, and the selection goals of the breed should be adjusted in order to reduce losses in genetic resources and to control inbreeding levels.

\section{ACKNOWLEDGMENTS}

Research supported by the Plant Genomics and Breeding Center of the Federal University of Pelotas, Coordination of Improvement of Higher Education Personnel (CAPES), and the National Council for Scientific and Technological Development (CNPq). We thank the Brazilian Association of Criollo Horse Breeders for providing the genotyping data.

\section{REFERENCES}

ABCCC (1941). Balanço de Crioula até 1941. In: Anais da ACCC. 9st edn. ABCCC, Pelotas.

ABCCC (2004). Capítulo III: Dos fins da associação. In: Estatuto da ABCCC. 9st edn. ABCCC, Pelotas.

Achmann R, Huber T, Wallner B, Dovc P, et al. (2001). Base substitutions in the sequences flanking microsatellite markers HMS3 and ASB2 interfere with parentage testing in the Lipizzan horse. Anim. Genet. 32: 52.

Binns MM, Holmes NG, Holliman A and Scott AM (1995). The identification of polymorphic microsatellite loci in the horse and their use in thoroughbred parentage testing. Br. Vet. J. 151: 9-15.

Bjornstad $\mathrm{G}$ and Roed KH (2002). Evaluation of factors affecting individual assignment precision using microsatellite data from horse breeds and simulated breed crosses. Anim. Genet. 33: 264-270.

Bomcke E and Gengler N (2009). Combining microsatellite and pedigree data to estimate relationships among Skyros ponies. J. Appl. Genet. 50: 133-143.

Bowling AT, Eggleston-Stott ML, Byrns G, Clark RS, et al. (1997). Validation of microsatellite markers for routine horse parentage testing. Anim. Genet. 28: 247-252.

Budowle B, Garofano P, Hellman A, Ketchum M, et al. (2005). Recommendations for animal DNA forensic and identity testing. Int. J. Legal Med. 119: 295-302.

Cardellino RA (2000). Animal genetics resource in southern Brazil. Arch. Zootec. 49: 327-331.

Dakin EE and Avise JC (2004). Microsatellite null alleles in parentage analysis. Heredity 93: 504-509.

Diaz S, Dulout FN and Peral-Garcia P (2002). Greater genetic variability in Argentine Creole than in Thoroughbred horses based on serum protein polymorphisms. Genet. Mol. Res. 1: 261-265.

Dimsoski P (2003). Development of a 17-plex microsatellite polymerase chain reaction kit for genotyping horses. Croat. Med. J. 44: 332-335.

Ellegren H, Johansson M, Sandberg K and Andersson L (1992). Cloning of highly polymorphic microsatellites in the horse. Anim. Genet. 23: 133-142.

FICCC (2010). La FICCC. FICCC/International Federation of Creole Horse Breeder. [http://www.ficcc.net/acerca. php?cod=1]. Accessed January 5, 2010.

Giacomoni EH, Fernandez-Stolz GP and Freitas TR (2008). Genetic diversity in the Pantaneiro horse breed assessed using 
microsatellite DNA markers. Genet. Mol. Res. 7: 261-270.

Guerin G, Bertaud M and Amigues Y (1994). Characterization of seven new horse microsatellites: HMS1, HMS2, HMS3, HMS5, HMS6, HMS7 and HMS8. Anim. Genet. 25: 62.

International Society of Animal Genetics. ISAG Species Panels 2003. Available at [http://www.isag.org.uk/Docs/02 PVpanels_LPCGH.doc]. Accessed January 5, 2010.

Jakabová D (2002). Effectiveness of six highly polymorphic microsatellite markers in resolving paternity cases in Thoroughbred horses in Slovakia. Czech J. Anim. Sci. 12: 497-501.

Jamieson A and Taylor SC (1997). Comparisons of three probability formulae for parentage exclusion. Anim. Genet. 28: $397-400$.

Kakoi H, Tozaki T and Gawahara H (2007). Molecular analysis using mitochondrial DNA and microsatellites to infer the formation process of Japanese native horse populations. Biochem. Genet. 45: 375-395.

Kalinowski ST, Taper ML and Marshall TC (2007). Revising how the computer program CERVUS accommodates genotyping error increases success in paternity assignment. Mol. Ecol. 16: 1099-1106.

Kelly L, Postiglioni A, De Andres DF, Vega-Pla JL, et al. (2002). Genetic characterisation of the Uruguayan Creole horse and analysis of relationships among horse breeds. Res. Vet. Sci. 72: 69-73.

Lee SY and Cho GJ (2006). Parentage testing of Thoroughbred horse in Korea using microsatellite DNA typing. J. Vet. Sci. 7: 63-67.

LeRoy G, Callede L, Verrier E, Meriaux JC, et al. (2009). Genetic diversity of a large set of horse breeds raised in France assessed by microsatellite polymorphism. Genet. Sel. Evol. 41: 5.

Luís C, Gus Cothran E and Oom EE (2002). Microsatellites in Portuguese autochthonous horse breed: usefulness for parentage testing. Genet. Mol. Biol. 25: 131-134.

Luis C, Cothran EG and Oom MM (2007a). Inbreeding and genetic structure in the endangered Sorraia horse breed: implications for its conservation and management. J. Hered. 98: 232-237.

Luis C, Juras R, Oom MM and Cothran EG (2007b). Genetic diversity and relationships of Portuguese and other horse breeds based on protein and microsatellite loci variation. Anim. Genet. 38: 20-27.

Marklund S, Ellegren H, Eriksson S, Sandberg K, et al. (1994). Parentage testing and linkage analysis in the horse using a set of highly polymorphic microsatellites. Anim. Genet. 25: 19-23.

Marshall TC, Slate J, Kruuk LE and Pemberton JM (1998). Statistical confidence for likelihood-based paternity inference in natural populations. Mol. Ecol. 7: 639-655.

Mirol PM, Peral GP, Vega-Pla JL and Dulout FN (2002). Phylogenetic relationships of Argentinean Creole horses and other South American and Spanish breeds inferred from mitochondrial DNA sequences. Anim. Genet. 33: 356-363.

Paredes M, Norambuena MC and Molina B (2009). Genetic diversity analysis in 12 microsatellite loci, used in equine paternity test in Chile. Arch. Zootec. 58: 111-116.

Perez-Gutierrez LM, De la Pena A and Arana P (2008). Genetic analysis of the Hispano-Breton heavy horse. Anim. Genet. 39: 506-514.

Plante Y, Vega-Pla JL, Lucas Z, Colling D, et al. (2007). Genetic diversity in a feral horse population from Sable Island, Canada. J. Hered. 98: 594-602.

Rousset F (2008). GENEPOP' 007: a complete re-implementation of the GENEPOP software for Windows and Linux. Mol. Ecol. Resour. 8: 103-106.

Solis A, Jugo BM, Meriaux JC, Iriondo M, et al. (2005). Genetic diversity within and among four South European native horse breeds based on microsatellite DNA analysis: implications for conservation. J. Hered. 96: 670-678.

Thirstrup JP, Pertoldi C and Loeschcke V (2008). Genetic analysis, breed assignment and conservation priorities of three native Danish horse breeds. Anim. Genet. 39: 496-505.

Tozaki T, Kakoi H, Mashima S, Hirota K, et al. (2001). Population study and validation of paternity testing for Thoroughbred horses by 15 microsatellite loci. J. Vet. Med. Sci. 63: 1191-1197.

van de Goor LH, Panneman H and van Haeringen WA (2010). A proposal for standardization in forensic equine DNA typing: allele nomenclature for 17 equine-specific STR loci. Anim. Genet. 41: 122-127.

van Haeringen H, Bowling AT, Stott ML, Lenstra JA, et al. (1994). A highly polymorphic horse microsatellite locus: VHL20. Anim. Genet. 25: 207.

Vila C, Leonard JA, Gotherstrom A, Marklund S, et al. (2001). Widespread origins of domestic horse lineages. Science 291: 474-477.

Waits LP, Luikart G and Taberlet P (2001). Estimating the probability of identity among genotypes in natural populations: cautions and guidelines. Mol. Ecol. 10: 249-256.

Weir BS and Cockerham CC (1984). Estimating F-statistics for the analysis of population structure. Evolution 38: 13581370. 